\title{
DEGENERATIVE TRENDS OF THE PALMARIS LONGUS MUSCLE IN A SOUTH AFRICAN POPULATION.
}

\author{
G. Venter, ${ }^{1,2}$ A.N. Van Schoor, ${ }^{2}$ and M.C. Bosman ${ }^{2}$ \\ ${ }^{1}$ Department of Anatomy, School of Pathology and Pre-clinical Science, Faculty of Health Sciences, \\ University of Limpopo (Medunsa Campus), South Africa \\ ${ }^{2}$ Department of Anatomy, School of Medicine, Faculty of Health Sciences, University of Pretoria, \\ South Africa
}

Number of figures: 3

Number of tables: 3

Abbreviated title: DEGENERATIVE TRENDS OF PALMARIS LONGUS

\section{Corresponding author:}

G. Venter, Department of Anatomy, School of Pathology and Pre-clinical Science, Faculty of Health Sciences, University of Limpopo (Medunsa Campus), Garankuwa, South Africa. Telephone number: +2712 521 4021, fax number: +2712 521 4512, e-mail: gerda.venter@ul.ac.za

\section{ABSTRACT}

The literature reports that the palmaris longus muscle $(\mathrm{PL})$ is only found in mammals in which the forelimbs are weight-bearing extremities. It is suggested that the function of this muscle has been taken over by the other flexors in the forearm. Terms used in the literature to describe the diminishing of this muscle include retrogressive or phylogenetic degenerative trends. The aims of this study were to determine the prevalence of $\mathrm{PL}$ in a South African population and whether a 
phylogenetic degenerative trend for the PL exists. To determine the prevalence of the PL, five groups, representing different age intervals (Years 0-20, 21-40, 41-60, 61-80 and 81-99) were used. A sample of 706 participants of various ages was randomly selected. Statistical analysis included comparisons of the prevalence of the muscle between males and females and left and right sides, using a student $t$ test. A Chi-squared test was used to determine a possible phylogenetic degenerative trend of PL within the five groups. The sample yielded a bilateral absence of the PL in $11.9 \%$ of the cases. The muscle was unilaterally absent on the left side in $7.65 \%$ and $6.94 \%$ on the right side. The Chi-squared tests revealed a $p$ value of 0.27 for the left arm and 0.39 for the right arm. No obvious trend could be established for the phylogenetic degeneration of the $\mathrm{PL}$ in this study. It would appear that the PL muscle should not be considered as a phylogenetically degenerating muscle in a South African population.

\section{KEYWORDS}

Palmaris longus, phylogenetic, degeneration, South Africa, retrogressive, trend

\section{INTRODUCTION}

The literature reports that the palmaris longus muscle is only found in mammals in which the forelimbs are weight-bearing extremities (Reimann et al., 1944). They further report that the regression of the palmaris longus muscle may be linked with the development of prehension. Terms used in the literature to describe the waning of this muscle include retrogressive or phylogenetic degenerative trends 
(Rubino et al., 1995, Williams, 1995, Vanderhooft, 1996, Sebastin et al., 2005, Pai et al., 2008).

Certain characteristics of the palmaris longus muscle suggest that this muscle is degenerating. It is said to be a "phylogenetic degenerative metacarpo-phalangeal joint flexor" (Williams, 1995). Sebastin and co-workers (2005) mention that the short muscular belly and long tendon are characteristic of a phylogenetic degenerative trend of this muscle. According to Sebastin et al., "The absence of a difference in strength in the normal population may indicate the gradual phylogenetic degenerative trend of this muscle" and that in those individuals without the palmaris longus, the function is taken over by other flexors in the forearm (p. 408). Mobbs and Chandran (2000) report that the palmar aponeurosis is replacing the distal tendon of the palmaris longus muscle. Pai et al., (2008) conclude that the palmaris longus muscle is a primitive muscle and its fibrofascial component characterizes phylogenetic degeneration.

The diversity of its origin is indicated by the variation in the frequencies of the absence of the palmaris longus muscle in different populations (Thompson et al., 1921). Kapoor and co-workers (2008) support this view by stating that the palmaris longus muscle is not diminishing as rapidly in the Indian population as in other populations.

Therefore, the aims of the study were firstly to determine the prevalence of the palmaris longus muscle in a sample of the South African population, and secondly, to determine whether a phylogenetic degenerative trend for this muscle exists. 


\section{MATERIALS AND METHODS}

To determine the prevalence of the palmaris longus muscle, five groups representing different age intervals, were used (see Table 1). The following demographic data of the sample population were recorded: age, sex and presence or absence of palmaris longus in one or both arms. The sample consisted of 706 individuals (363 males and 343 females) between the ages of 5 and 99 years. Participants represented a sample of a modern South African population, which included socially identified racial groups including: black, white, Asian, Indian and South African "coloured" (heterogeneous ethnic group who possess ancestry from Europe and Africa) individuals.

Ethical clearance to conduct this study was obtained from the Student Ethics Committee of the Faculty of Health Sciences, University of Pretoria. All volunteers signed an informed consent form prior to participation in this study.

Table 1: Distribution of the sample in the various age groups.

\begin{tabular}{c|ccccc}
\hline & $\begin{array}{c}\text { Group 1 } \\
(0-20 \mathrm{yrs})\end{array}$ & $\begin{array}{c}\text { Group 2 } \\
(21-40 \mathrm{yrs})\end{array}$ & $\begin{array}{c}\text { Group 3 } \\
(41-60 \mathrm{yrs})\end{array}$ & $\begin{array}{c}\text { Group 4 } \\
(61-80 \mathrm{yrs})\end{array}$ & $\begin{array}{c}\text { Group 5 } \\
(81-99 \mathrm{yrs} .)\end{array}$ \\
\hline $\mathbf{n}$ & 361 & 151 & 93 & 64 & 37 \\
\hline
\end{tabular}


Schaeffer's test was used in order to visualize or palpate the palmaris longus tendon. Participants were asked to oppose their thumb and fifth digit with slight flexion of the wrist. If the palmaris longus tendon was present, it would be visible at the distal aspect of the forearm (see Figure 1).

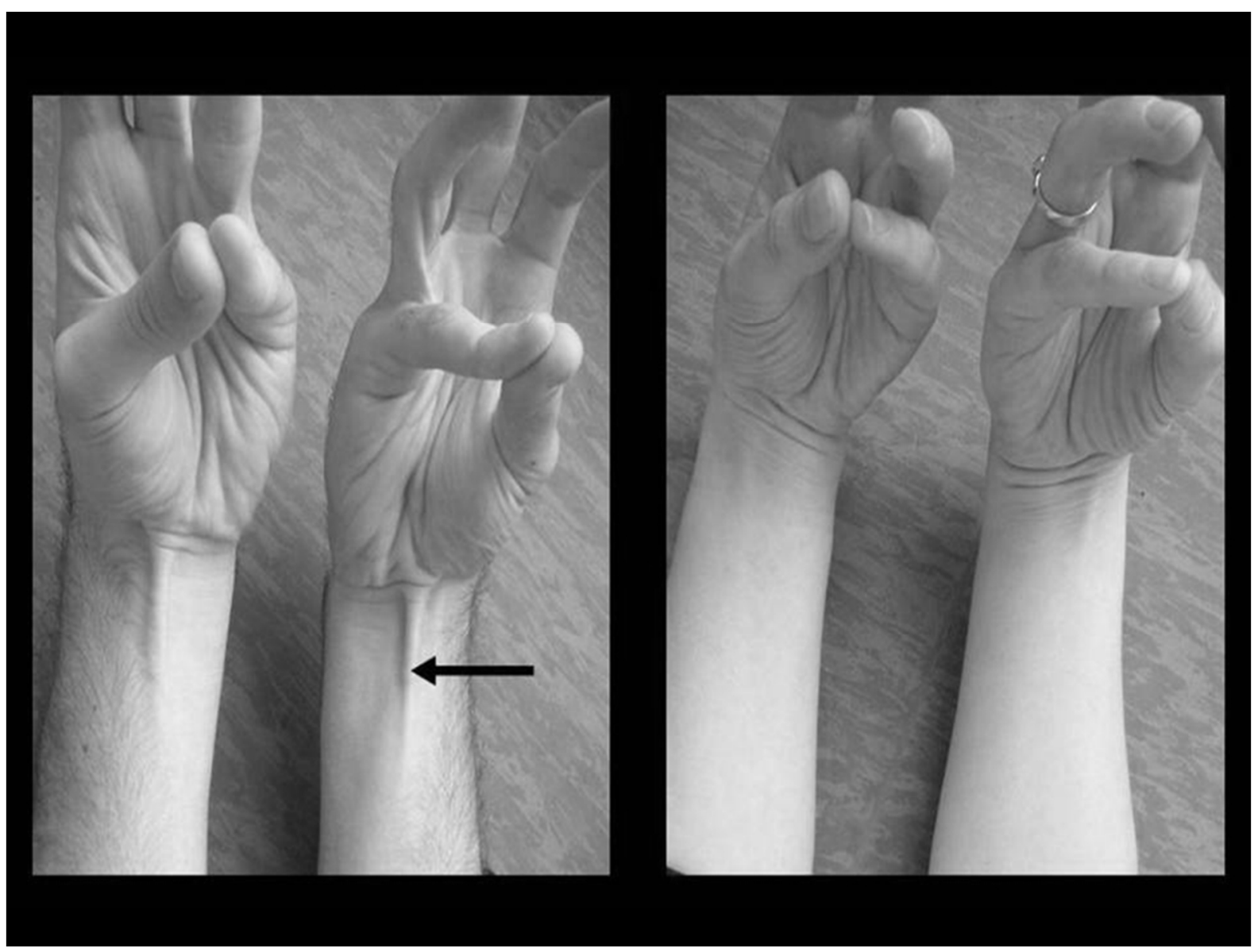

Figure 1: Prevalence of the palmaris longus muscle. The individual on the left exhibits the palmaris longus muscle bilaterally, and the individual on the right has the muscle bilaterally absent.

To determine a possible phylogenetic degenerative trend for the palmaris longus muscle, the data obtained from the five groups were statistically analyzed by means of a Chi-squared test. The hypothesis is that there is a phylogenetic degenerative trend of the palmaris longus muscle in the South African population. This hypothesis can be proved by determining the presence or absence of the muscle in young versus older subjects. The null-hypothesis: there is no phylogenetic 
degenerative trend of the palmaris longus muscle in the sample of the South African population. The null-hypothesis will be true if there is no statistical difference in the prevalence of the muscle, between the five age groups.

\section{$\underline{\text { RESULTS }}$}

The prevalence of the palmaris longus muscle in the sample of 706 participants is summarized in Table 2.

Table 2: Table showing the prevalence of the palmaris longus muscle for the sample examined.

\begin{tabular}{c|ccc}
\hline & $\begin{array}{c}\text { Total sample } \\
(\mathrm{n}=706)\end{array}$ & $\begin{array}{c}\text { Males } \\
(\mathrm{n}=363)\end{array}$ & $\begin{array}{c}\text { Females } \\
(\mathrm{n}=343)\end{array}$ \\
\hline Bilateral absence & $11.9 \%$ & $6.52 \%$ & $5.38 \%$ \\
Absent on left side & $7.65 \%$ & $3.54 \%$ & $4.11 \%$ \\
Absent on right side & $6.94 \%$ & $4.25 \%$ & $2.69 \%$ \\
Bilateral presence & $73.51 \%$ & $34.28 \%$ & $39.24 \%$ \\
\hline
\end{tabular}

Figures 2 and 3 indicate the prevalence of the palmaris longus muscle, for both the left and right arms, in the different age groups. 

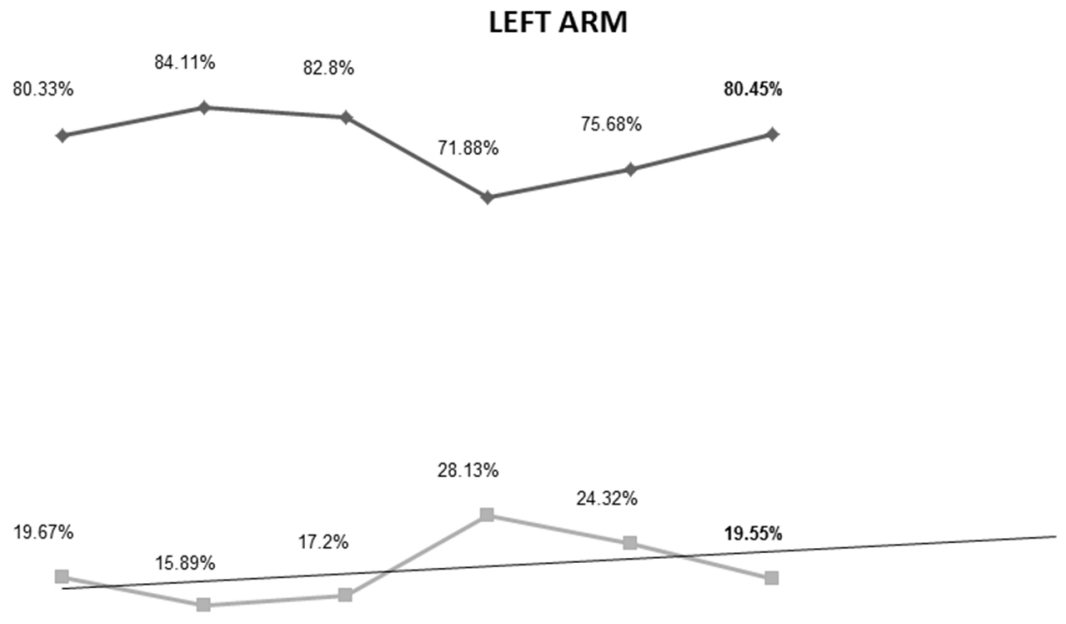

Group 1 Group 2 Group $3 \quad$ Group $4 \quad$ Group 5 Total sample

Figure 2: Prevalence of the palmaris longus muscle in the different age groups for the left arm.

\section{RIGHT ARM}
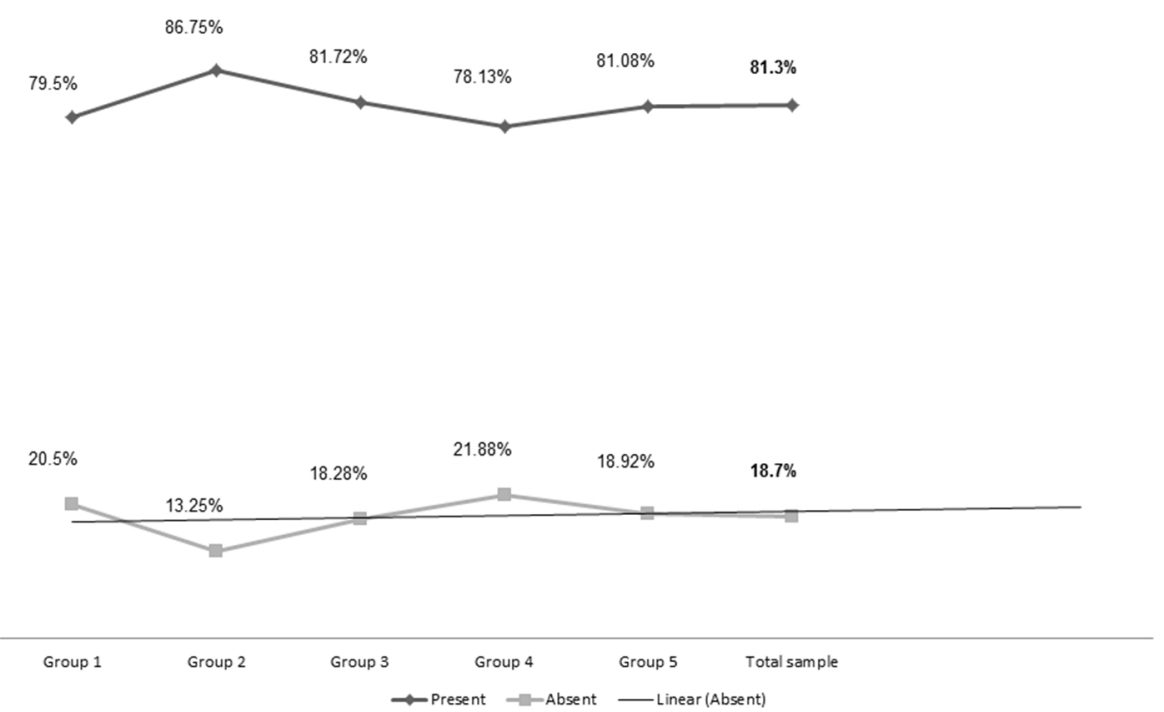

Figure 3: Prevalence of the palmaris longus muscle in the different age groups for the right arm. 
In age group 1, 361 individuals were investigated. It was found that $80.33 \%$ $(n=290)$ of individuals had the muscle in the left arm and $79.5 \%(n=287)$ in the right arm. The second age group consisted of 151 individuals. Of these subjects $84.11 \%$ $(n=127)$ had the muscle in the left arm and $86.75 \%(n=131)$ in the right arm. Age group number 3 had 93 individuals. The muscle was present in $82.8 \%(n=77)$ of the individuals on the left side, and $81.72 \%(n=76)$ on the right side.

In the fourth age group, the sample size was 64 individuals. Of the individuals, $71.9 \%(n=46)$ had the palmaris longus muscle present on the left side and $78.13 \%$ $(n=50)$ of the muscles on the right side. The fifth and final age group consisted of 37 individuals of whom $75.68 \%(\mathrm{n}=28)$ had the palmaris longus muscle present on the left side and $81.08 \%(n=7)$ on the right side.

In total, $80.45 \%(n=568)$ of individuals had the palmaris longus muscle present in the left arm, compared to the right arm with a presence of $81.3 \%(n=574)$ of individuals. The palmaris longus muscle was absent in $19.55 \% \quad(n=138)$ of individuals on the left and $18.7 \%(n=132)$ of individuals on the right side.

The Chi-squared tests, concerned with the different age groups, also revealed a p-value of 0.27 for the left arm and 0.39 for the right arm. In Figures 1 and 2, a linear trend-line was inserted to indicate a possible trend in the absence of the palmaris longus muscle in the various age groups. However, to reveal a possible phylogenetic degenerative trend, there should be a larger number of absences of palmaris longus in age group 1 than in group 5, i.e., a clear negative linear regression line through the different age groups. This is not the case and the 
hypothesis is therefore rejected. In this study representing a South African population, no obvious trend could be established that would indicate phylogenetic degeneration of the palmaris longus muscle.

\section{DISCUSSION}

The literature mentions various characteristics of the palmaris longus muscle that are indicative of its disappearance with time (Reimann et al., 1944, Rubino et al., 1995, Vanderhooft et al., 1996, De Smet, 2002, Sebastin et al., 2005, Natsis et al., 2007, Kapoor et al., 2008, Nayak et al., 2008, Georgiev et al., 2009, Stecco et al.,

2009). These include: the muscle proposed to be a metacarpo-phalangeal joint flexor (Williams, 1995); a large amount of variation in its attachment (Mobbs \& Chandran, 2000 ); changes in the structure of the muscle such as an increase in the length of the tendon and a decrease in the size of the muscle belly (Sebastin et al., 2005) and the varying frequencies of the muscle among different races and/or populations (see Table 3) (Thompson et al., 1921).

A bilateral absence of the palmaris longus muscle was found in $11.9 \%$ of the South African sample, which, except for the study conducted by Kapoor et al. (2008) on an Indian population (bilateral absence in 17.2\%) and Oluyemi et al. (2008) on an Nigerian population (bilateral absence in $18.75 \%$ ), is slightly higher when compared to previous studies that yielded a bilateral absence ranging between $2.0 \%-9.7 \%$ (see Table 3) (Reimann et al., 1944, Vanderhooft, 1996, Thompson et al., 2002, Sebastin et al., 2005). 
Table 3: Prevalence of the palmaris longus muscle, a comparison between the different studies found in the literature.

\begin{tabular}{|c|c|c|c|c|c|c|c|c|c|}
\hline \multirow[t]{2}{*}{ Author } & \multirow{2}{*}{$\begin{array}{c}\text { Total } \\
\text { sample } \\
\text { (n) }\end{array}$} & \multicolumn{2}{|c|}{$\begin{array}{c}\text { Present } \\
\text { bilaterally }\end{array}$} & \multicolumn{2}{|c|}{$\begin{array}{c}\text { Absent } \\
\text { bilaterally }\end{array}$} & \multicolumn{2}{|c|}{$\begin{array}{c}\text { Unilateral } \\
\text { absence } \\
\text { (left) }\end{array}$} & \multicolumn{2}{|c|}{$\begin{array}{c}\text { Unilateral } \\
\text { absence (right) }\end{array}$} \\
\hline & & $n$ & $\%$ & $\mathrm{n}$ & $\%$ & $n$ & $\%$ & $\mathbf{N}$ & $\%$ \\
\hline $\begin{array}{l}\text { North American population } \\
\text { (Reimann et al., 1944) }\end{array}$ & 362 & 302 & 83.4 & 30 & 8.3 & 13 & 3.6 & 17 & 4.7 \\
\hline $\begin{array}{l}\text { Amazon Indian population } \\
\text { (Machado \& Di Dio, 1967) }\end{array}$ & 379 & - & - & 10 & 2.6 & - & - & - & - \\
\hline $\begin{array}{l}\text { North American population } \\
\text { (Wehbé \& Mawr, 1992) }\end{array}$ & 120 & - & - & 6 & 5.0 & - & - & - & - \\
\hline $\begin{array}{l}\text { North American population } \\
\text { (Vanderhooft, 1996) }\end{array}$ & 186 & 156 & 83.9 & 18 & 9.7 & 0 & 0.0 & 4 & 2.2 \\
\hline $\begin{array}{l}\text { European population } \\
\text { (Thompson et al., 2002) }\end{array}$ & 300 & 228 & 76.0 & 26 & 8.7 & 20 & 6.7 & 29 & 9.7 \\
\hline $\begin{array}{l}\text { Asian population } \\
\text { (Sebastin et al., 2005) }\end{array}$ & 418 & 394 & 94.3 & 7 & 2.0 & 12 & 2.9 & 5 & 1.2 \\
\hline $\begin{array}{l}\text { Malaysian population } \\
\text { (Roohi et al., 2007) }\end{array}$ & 450 & - & - & 13 & 2.9 & - & - & - & - \\
\hline $\begin{array}{l}\text { Indian population } \\
\text { (Kapoor et al., 2008) }\end{array}$ & 500 & 414 & 82.8 & 40 & 17.2 & 31 & 6.2 & 15 & 3.0 \\
\hline $\begin{array}{l}\text { Iranian population } \text { (Mobarakeh } \\
\text { et al., 2008) }\end{array}$ & 64 & - & - & 5 & 7.8 & - & - & - & - \\
\hline $\begin{array}{l}\text { Nigerian population } \quad \text { (Oluyemi et } \\
\text { al., 2008) }\end{array}$ & 600 & 188 & 31.3 & 112 & 18.8 & 150 & 25.0 & 150 & 25.0 \\
\hline $\begin{array}{l}\text { Southern Indian population (Pai } \\
\text { et al., 2008) }\end{array}$ & 30 & - & - & 1 & 3.3 & 3 & 10 & - & 0 \\
\hline $\begin{array}{l}\text { Zimbabwean population } \\
\text { (Gangata, 2009) }\end{array}$ & 890 & - & - & 5 & 0.6 & - & - & - & - \\
\hline $\begin{array}{l}\text { South African population } \\
\text { (Current study, 2012) }\end{array}$ & 706 & 519 & 73.5 & 84 & 11.9 & 54 & 7.7 & 49 & 6.9 \\
\hline
\end{tabular}


As seen in Figures 2 and 3, age groups number four and five have the highest incidence of absence of the palmaris longus muscle, although not significantly different statistically. These were individuals between the ages of 61 and 99 years old. Should a degenerative trend exist, one would expect the absence of this muscle to be more prevalent in the younger age groups (i.e., age groups one and two) and that there should be a higher incidence of the absence of the palmaris longus muscle when compared to age groups four and five.

To conclude several factors would normally suggest that palmaris longus muscle should be progressively disappearing in younger age groups, however this is not the case in this specific study. There was no statistical evidence that could prove a degenerative trend in a South African population. It would therefore appear that the palmaris longus muscle should not be considered as a phylogenetically degenerating muscle in a South African population.

\section{REFERENCES}

De Smet L., 2002, Median and ulnar nerve compression at the wrist caused by anomalous muscles, Acta Orthopaedica Belgica, 68(5):431-436.

Gangata H.,2009, The Clinical Surface Anatomy Anomalies of the Palmaris Longus Muscle in the Black African Population of Zimbabwe and a Proposed New Testing Technique, Clin. Anat, 22:230-235. 
Georgiev GP, Jelev L and Ovtscharoff WA., 2009, Unusual combination of muscular and arterial variations in the upper extremity: a case report of a variant palmaris longus and an additional tendinous portion of the flexor carpi ulnaris together with a persistent median artery, Anatomy, 3:58-61.

Kapoor SK, Tiwari A, Kumar A, Bhatia R, Tantuway V and Kapoor S., 2008, Clinical relevance of palmaris longus agenesis: Common anatomical aberration, Anat Sci Int, 83:45-8.

Machado ABM and Di Dio LJA.,1967, Frequency of the Musculus Palmaris Longus Studied in Vivo in some Amazon Indians, Am J Phys. Anthrop, 27:11-20.

Mobarakeh MK, Pasha MG and Poor MM., 2008, Variation, Length and Width of Tendinous Portion of Palmaris Longus and Forearm Length and Height: Is there a link? A Cadaver Study of Adult Iranians, Iran J Med Sci, 33(3):164168.

Mobbs RJ and Chandran KN., 2000, Variation of palmaris longus tendon, Aust New Zeal J, 70:538.

Natsis K, Levva S, Totlis T, Anastasopoulos N and Paraskevas G., 2007, Threeheaded reversed palmaris longus muscle and its clinical significance, Ann Anat, 189:97-101. 
Nayak SR, Krishnamurthy A, Ramanathan LA, Prabhu LV, Kumar CG, Tom DK and Joy T., 2008, Multiple muscular anomalies of upper extremity: a cadaveric study, Rom J Morphol Embryol, 49(3):411-415.

Oluyemi KA, Adesanya OA, Odion BI and Ukwenya VO., 2008, Incidence of palmaris longus muscle absence in Nigerian population, Int J Morphol, 6(2):305-308.

Pai MM, Prabhu LV, Nayak SR, Madhyastha S, Vadgaonkar R, Krishnamurthy A and Kumar A., 2008, The palmaris longus muscle: its anatomic variations and functional morphology, Rom J Morphol Embryol, 49(2):215-217.

Reimann AF, Daseler EH, Anson BJ and Beaton LE., 1944, The palmaris longus and tendon. A study of 1600 extremities, Anat Rec, 89:495-505.

Roohi SA, Choon-Sian L, Shalimar A, Tan GH and Naicker As., 2007, A Study on the Absence of Palmaris Longus in a Multi-racial Population, M OrthoJl, 1(1):26-28.

Rubino C, Paolini G and Carlesimo B., 1995, Accessory Slip of the Palmaris Longus Muscle, Ann Plast Surg, 35:657-659.

Sebastin SJ, Lim AYT, Bee WH, Wong TCM and Methil BV., 2005, Does the absence of the palmaris longus affect grip and pinch strength?, J Hand Surg, 30B:406-408. 
Stecco C, Lancerotto L, Porzionato A, Maccchi V, Tiengo C, Parenti A, Sanudo JR and De Caro R., 2009, The palmaris longus muscle and its relations with the antebrachial fascia and the palmar aponeurosis, Clin Anat, 22:221-229.

Thompson JW, McBatts J and Danforth $\mathrm{CH}$., 1921, Hereditary and racial variation in the musculus palmaris longus, Amer J Phys Anthrop, 4(2):205-219.

Thompson NW, Mockford BJ, Rasheed T and Herbert KJ., 2002, Functional absence of flexor digitorum superficialis to the little finger and absence of palmaris longus - Is there a link?, J Hand Surg, 27B:433-434.

Vanderhooft E., 1996, The Frequency of and Relationship Between the Palmaris Longus and Plantaris Tendons, Am J Orthop, 1:38-41.

Wehbé MA, and Mawr B., 1992, Tendon graft donor sites, J Hand Surg, 17A:11302.

Williams PL, editor, 1995, Gray's Anatomy: The anatomical basis of medicine and surgery, $38^{\text {th }}$ ed, New York, Churchill Livingstone. 